\title{
Architectural design strategies for infection prevention and control (IPC) in health-care facilities: towards curbing the spread of Covid-19
}

\author{
Udomiaye Emmanuel $^{1}$ (D) $\cdot$ Eze Desy Osondu $^{1} \cdot$ Kalu Cheche Kalu $^{1}$ \\ Received: 5 June 2020 / Accepted: 24 October 2020 / Published online: 30 October 2020 \\ (C) Springer Nature Switzerland AG 2020
}

\begin{abstract}
Background Sustainable design strategies are targeted at finding architectural solutions that reassure the well-being and coexistence of inorganic features, living organisms, and humans that make up the ecosystem. The emergence of the novel coronavirus, an increase in microbial resistance, and lack of a vaccine for the present pandemic have made it imperative to appraise the preventive strategies employed during the pre-antibiotic period. Sustainable architecture for children's hospital design and childcare facilities, apart from low energy and carbon emission, must integrate design strategies to confront the impact of infectious diseases.

Aim The aim of the paper is to identify how the space patients and health-care workers 0 occupy can be made safer from an architectural design perspective with the view of developing guidelines for policymakers and highlighting the architect's role in combating the pandemic.

Objectives The objectives include; to examine the evolution of medical architecture and the nexus between infectious diseases and architectural space and suggest a design approach that enhances infection prevention and control (IPC).

Method The paper relied on existing literature, interviews, and interactions with healthcare workers.

Results/Conclusion The findings showed that design strategies have always played a significant role in infection prevention and control (IPC) and could as well be a panacea for curbing the spread of Covid -19 .
\end{abstract}

Keywords Architecture $\cdot$ Building $\cdot$ Control $\cdot$ Covid-19 $\cdot$ Infection $\cdot$ Sustainable

\section{Introduction}

Sustainable architecture is the adoption of efficient energy and material resources in buildings, incorporation of the dwellers into micro-climate control and the natural environment. The purpose of sustainable design is to find architectural responses, promote the well-being/coexistence of inorganic elements, living organisms and humans that make up the ecosystem [1]. The architectural design process of a healthca

re facility should be an integral part of infection prevention and control mechanism. Van-Khai [2] added that the

Udomiaye Emmanuel

udomiaye@gmail.com

Eze Desy Osondu

osondudesy@gmail.com

Kalu Cheche Kalu

chechekalu@yahoo.com

1 Department of Architectural Technology, Akanu Ibiam Federal Polytechnic, Uwana, Nigeria goal of sustainable architecture for hospital design apart from low energy and low carbon emission, it must integrate design strategies for infectious disease prevention and control (IPC). According to World Health Organization (WHO), infection disease prevention and control (IPC) is a scientific method and hands-on solution intended to avert harm or health dangers initiated by infection to patients and health workers [3]. In the epidemic of widely drug-resistant tuberculosis which occurred in 2006 in Tugela Ferry-South Africa, the architectural design of the hospital building took a significant share of the blame [4]. The implication is that human health and wellbeing are intrinsically connected to the built environment. According to a recent report by the Center for Disease Control (CDC) with regard to the mode of Covid-19 mode of transmission and in collaboration with Lateef [5] it is has become imperative for a balance between the concept of open access design and the need for control measures to lessen the rate of infections. Studies have shown that climate change and unstable climate is not only influencing the built environment but plays a significant role in driving the global emergence, resurgence and redistribution of infectious diseases $[6,7]$. 
In the quest for more ventilators, Personal Protective Equipment (PPE) and extensive behavioral change [8] professionals of all credentials need to come together to fight the COVID-19 pandemic. At present, there is a paucity of effective and contextual design strategy to support infection control and make healthcare workers much safer. Therefore, the aim of the paper is to examine how the space we occupy can be made safer from an architectural design perspective with the view of developing guidelines for policymakers and highlighting the architect's role in tackling the infections. The objectives include; to examine the evolution of medical architecture, the nexus between infectious diseases and architectural space, and suggest design approaches for infection prevention and control (IPC). The study relied on existing literature, interviews and interactions with health workers. Without a doubt, the present pandemic has revolutionized our thoughts with regard to hospital architectural design and planning.

\section{Review of evolution of medical architecture and infectious diseases}

The architecture of hospitals has been evolving from time to time to fit into the demands of the healing process. According to Guenther\&Vittori [9] and Cameron [10], there exists a longrecognized relationship between health and architecture, they added that the relevance of suitable building in the healing process is well known to both medical and architectural professionals.

In the early Middle Age, hospitals were dominated by social functions as against medical after the fall of the ancient states, owed to the low level of medical knowledge [11]. Nevertheless, in Western Europe, between the 6th and 8th centuries, numerous hospitals were launched. Well along, the understanding of classical and Eastern healers began to infiltrate Europe around the 12th-13th centuries [12]. The earliest chronicles of health-care in Egypt and Greece are knotted to spiritual tenets with priests and sanctuaries playing key parts in an attempt at disease identification, analysis and care. Many of the early hospital designs resembled schools structured around a courtyard often located at the edge of villages or cities and monastic orders were the caretakers of the sick [11, 13]. A good example of such a building is "Schola Medica Salernitana founded in the $9^{\text {th }}$ century under the auspices of the monastic hospital in Italy" [10]. Tesler [11] added that until the thirteenth century, this institute remains the pioneering epicenter for training healthcare personals, scientists and issuance of practice licenses in Europe.

Costeira [14] posited that the aspect of the contemporary hospital was configured between the 17th and 18th centuries in Europe. This is evident in the Hotel-Dieu, one of the earliest and biggest hospitals in Paris in the mid-1700s. The facility depreciated to a horrifying condition characterized by dark, poorly ventilated, unsanitary and the hospital wards were frequently located head-to-head to other wards with infectious patients. Therefore, a commission was set up to examine architectural design suitable for the circumstance, direct studies and researches to find a decisive solution to the hospital [13]. The confluence of events, the commission's outcome, and the notable works of Dr. Tenon gave birth to a solution to the problem known as the "pavilion" plan, which was first applied in the Hospital Lariboisiere constructed in 1854 [15].

Another crucial factor that revolutionized medical architecture was the discovery of the transmission of germs in 1860 [14]. This resulted in the isolation of disease and patients in a particular pavilion. The work of Louis Pasteur confirmed the need to tackle infection and disease transmission with the separation of patients and sterilization of medical devices [16]. The philosophies of isolating pathologies led to a true revolution in medical architecture. The emergence of the pavilion model and the rise of scientific medicine coupled with the specific task of giving attention to the environment of healthcare is the origin of contemporary hospital architecture. Worthy of mention is Florence Nightingale (1820-1910) born in Florence, Italy [13]. Through her revolutionary activities in nursing, writing and statistic, hospital development was significantly influenced [17].. Her experience in the Crimean War (1853-1856) established bases for healthcare with pavilion models that provides ventilation, circulation of patients, lighting, and hygiene. This further enhanced patient recoveries and lessened the rate of infections. This model retained the multiple patient ward concept often called the Nightingale ward as shown in Figs. 1 and 2 and are still applicable in today's practice.

Studies on the works of Florence Nightingale revealed that in the military hospital in Turkey during the Crimean, the number of soldiers that died from Nosocomial infections (typhus, cholera, and dysentery) are more than the number of soldiers who died as a result of injuries sustained in battle

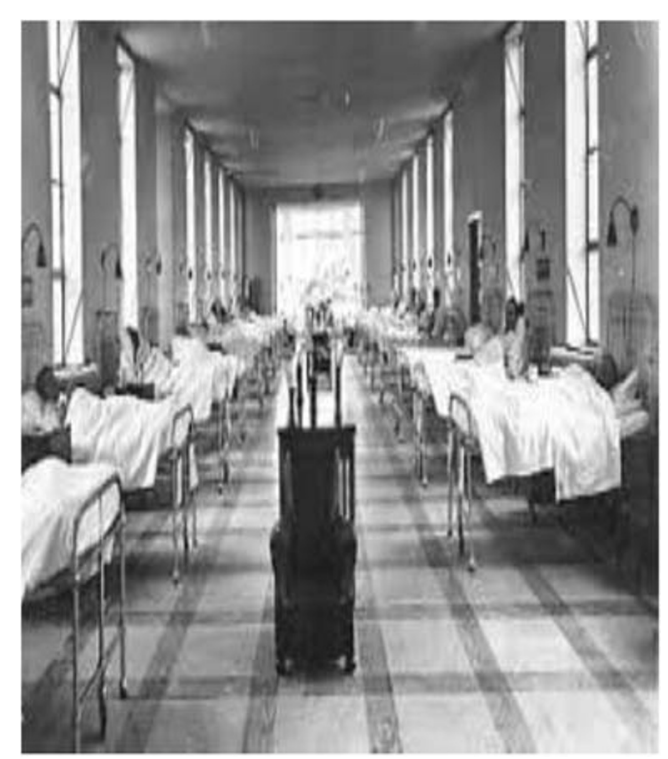

Fig. 1 Typical Nightingale Ward [18] 
Fig. 2 Pavilion model [18]

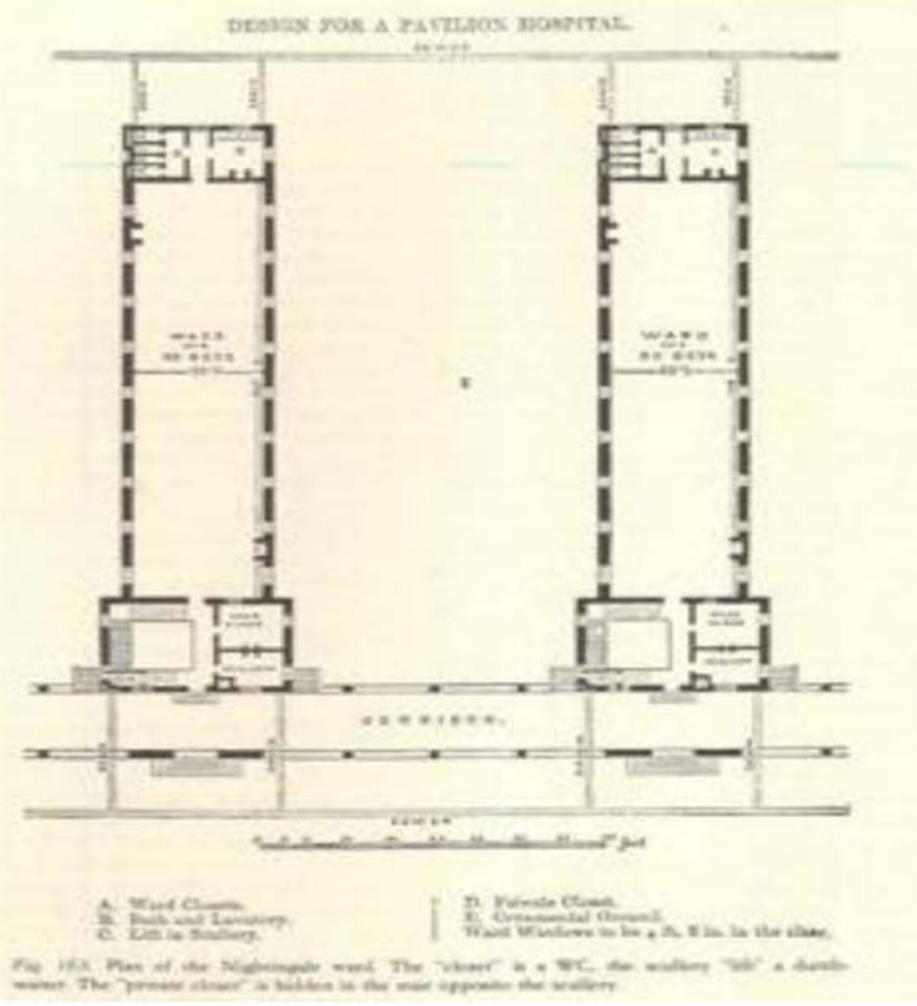

[17].. As a result of her discovering of the link between environmental/space factors and patients healing, death rates were drastically reduced (from $42 \%$ to less than $3 \%$ ) [19].

To some extent, the experiences of the epidemics of the recent past (TB, SARS, And Coronavirus) have thought us some lessons with regard to how architecture can be integrated into the fight against the spread of infectious diseases. Hence, we examine their major modes of transmission: air, water and surfaces.

\section{Methods of infectious diseases transmission}

In the outbreak of Tugela Ferry, South Africa, in 2006, the hospital management reported that the health facility was not designed to handle the airborne infection, rather it was designed with blood-borne infections in mind. As a result, it never had an airborne infection control policy at the time XDR-TB surfaced in patients [3]. The report underscores the distinctive role architects play in contributing to healthcare delivery. Thus, to understand measures to take in curbing infections from an architectural perspective, the modes of infection transmission need to be examined.

\section{Airborne and Droplet Transmission}

Indoor spaces or environments such as homes, offices, schools, workplaces, hospitals and terminals have possibly harmful pollutants [20]. Airborne transmission happens as soon as fine microbial particles comprising of pathogens stay up in the air for a long period, spread extensively by air flows and may cause infection when a vulnerable person inhales the infectious airflow [5]. There is growing anxiety that the coronavirus is aerosolized. Debatably, like the bacteria that causes $\mathrm{TB}$, it can remain up in the air and be inhaled by susceptible persons [21]. Viruses are small (20-400 nm), obligate intracellular parasites and they represent a common cause of infectious disease acquired indoors, as they are easily transmitted mainly in crowded, inadequately ventilated spaces or environments $[20,22]$. Droplet transmission takes place when viruses travel on comparatively large respiratory droplets $(>10 \mu \mathrm{m})$ that people sneeze, cough, or exhale when talking or breathing - primary aerosolization [20]. Giuseppina et al. [20] added that a single cough or sneeze in a corridor, lobby, or passage can discharge thousands of droplets, (up to 40,000) at speed of up to 50-200 miles per hour, each droplet comprising millions of viral particles. Droplet transmission is not the same as airborne transmission, droplets does not remain suspended in the air and aerosol droplets travel only small distances (1-2 m) before settling on surfaces [23].

\section{Waterborne transmission}

Diseases related to water are classified into four groups: water-borne, water-washed, water-based and waterrelated diseases [24]. Waterborne transmission is an effective means for increasing infectious agents to a huge 
percentage of the population. There are numerous waterrelated methods of spreading infectious diseases. For instance, large quantities of an enteric organisms can be discharged into the aquatic environment through the release of infected persons' waste (liquid or solid) into unprotected waterways [25]. Secondly, communicable substances from confined to bed infected persons can play a part in waterborne diseases transmission since pathogens in soiled bedding and clothing can also be discharged into the water in the course of laundry activities [26].

\section{Contact or Surface Transmission}

Infectious diseases can be transmitted from person to person by 'direct or indirect contact'. Direct contact means 'person-to-person' spread of diseases through physical contact between an infected person or infectious agents including contaminated hands, gloves, or mucous membranes of the receiver [5]. Indirect contact arises when a vulnerable person comes in contact with the infected object. Some organisms can live on objects for a short time. For example, coronavirus (Covid-19) can live for $72 \mathrm{~h}$ on a plastic surface, $24 \mathrm{~h}$ on cardboard surface and the Copper surface for $4 \mathrm{~h}$ [23]. The implication is touching an object such as handrails, door handles, shortly after an infected person, you might be open to infection. However, transmission takes place as you touch your mouth, nose, or eyes before washing your hands.

\section{Appropriate design strategies for infection prevention and control}

When architectural spaces are conceptualized and designed with a clear goal, such space can promote or aid the inhibition of infectious diseases. This was first experimented with by Florence Nightingale, when she launched the hospital ward model, stated that natural daylight and cross ventilation are significant components to disinfect and lessen the infection occurrence in hospitals [19]. Below are some design strategies to employ in adapting our domestic, commercial, residential, and hospital spaces for infection, prevention, and control.

\section{Design for social distancing}

Provide adequate spacing in waiting areas, corridors, hallways, stair and entrance lobby to support social distancing of at least $1000 \mathrm{~mm}$ apart. This will not only reduce contact transmission but will create safe distancing since current research reveals that aerosol droplets travel only short distances of $1000 \mathrm{~mm}$ to $2000 \mathrm{~mm}$ before settling on surfaces [22]. Corridors should be designed to discourage informal conversations by eliminating nook with bench or ledge as shown in fig. 3 . The ledge corridor design was earlier introduced to hospital design by Carthey [27] to encourage interactions among team members.

Avoid closed-end lobbies, waiting areas, double bank corridors and other spaces designed with little or no airflow.

It has become obvious that corridor and lobby design considerations need to be reviewed to accommodate not only wheelchairs, crouches, trolleys, and beds but also safe distancing as required by CDC. As seen in Fig. 4, a corridor width of $1500 \mathrm{~mm}$ recommended by the UK Department of Health [28] is inadequate with regard to safe distancing within hospital space. Hence, this study suggests a minimum of $2600 \mathrm{~mm}$ width for corridors as analyzed in Fig. 5. This is to allow for $1000 \mathrm{~mm}$ minimum interval in social distancing and $300 \mathrm{~mm}$ as bilateral freeboards since human movement is not exactly in a straight line.

\section{Design to enhance natural ventilation}

Ventilation considerably is the movement of air within a space, often shaped by variance in air pressure. Ventilation is very critical in mitigating nosocomial and other infectious diseases. Recent studies have shown that an appropriate ventilation rate can effectively decrease the cross-infection risk of airborne infections in healthcare facilities and public spaces $[29,30]$. Natural ventilation can provide a higher ventilation rate than power-driven ventilation in an energy-efficient manner. A study of isolation wards in Chinese hospitals revealed that those with a high percentage of openable openings were found to be better in preventing the plague of SARS among health workers than other available design [31]. Ventilation rate requirement- $\mathrm{ACH}$ by $\mathrm{CDC}$ is $12 \mathrm{ACH}$ [32], the implication is that when the ventilation rate $(\mathrm{ACH}$-Air Change per Hour) increases, the infection risk would be significantly reduced.

A Study by Hua et al. [30] revealed that the decay of droplet nuclei concentration is significantly influenced by ventilation rate. Hua et al. [30] with the concentration decay equation, observed that it requires $20 \mathrm{~min}$ to lessen the concentration to $1.8 \%$ with $12 \mathrm{ACH}$, on the other hand only 10 min with $24 \mathrm{ACH}$. As presented in Table 1.

In another study, Escombe, Eduardo, Victor, Manuel, \& David [33] adopted the carbon dioxide tracer-gas technique to analyzed the pre- and post- modification scenarios of a room. The aim was to examine the change in TB transmission risk in the consulting room and waiting room. The result indicated an average $72 \%$ decline (interquartile range 51-82\%) in estimated TB transmission risk for patients and healthcare personals. Thus, adequate ventilation could be a panacea for curbing the spread of infectious diseases such as covid-19 in hospitals, schools, offices and other public spaces. Also, the study suggests the following design measures; 
Fig. 3 Example of corridor nook earlier proposed and being use by some hospitals [27]

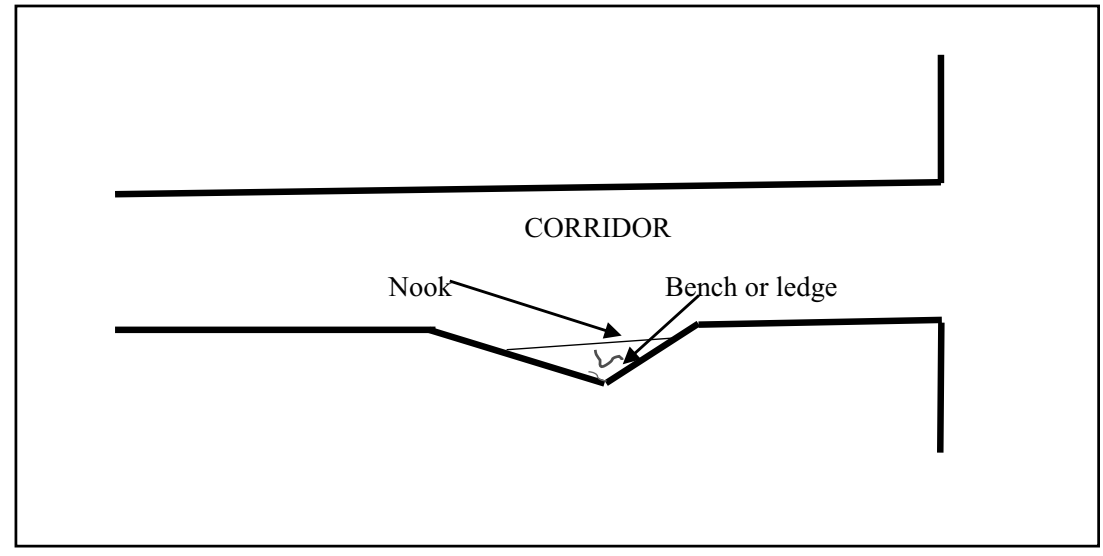

- Adequate cross ventilation in healthcare facilities is necessary.

- Corridors should have open-end to ensure appropriate ventilation rate as shown in fig. 6 . As much as possible, corridors or hallways with a closed end should be avoided. Provide an upper ventilation window on the dividing wall in the hallway and ventilation louver on the doorstop to lessen hot air circulation.

- Integrate the courtyard design to establish a cohesive ventilation passage, use the courtyard space as the ecological interchange space, conduct overall design on building structure layer/open space and create an integrated ventilation channel to enable the natural ventilation of hospital building as shown in fig. 7 . The design approach (open-end corridor and courtyard) increases ventilation rate $(\mathrm{ACH}-$ air change per hour) thereby reducing the risk of infection significantly. Where natural ventilation is inadequate, mixed-mode (Hybrid) approach and approved mechanical ventilation should be adopted.

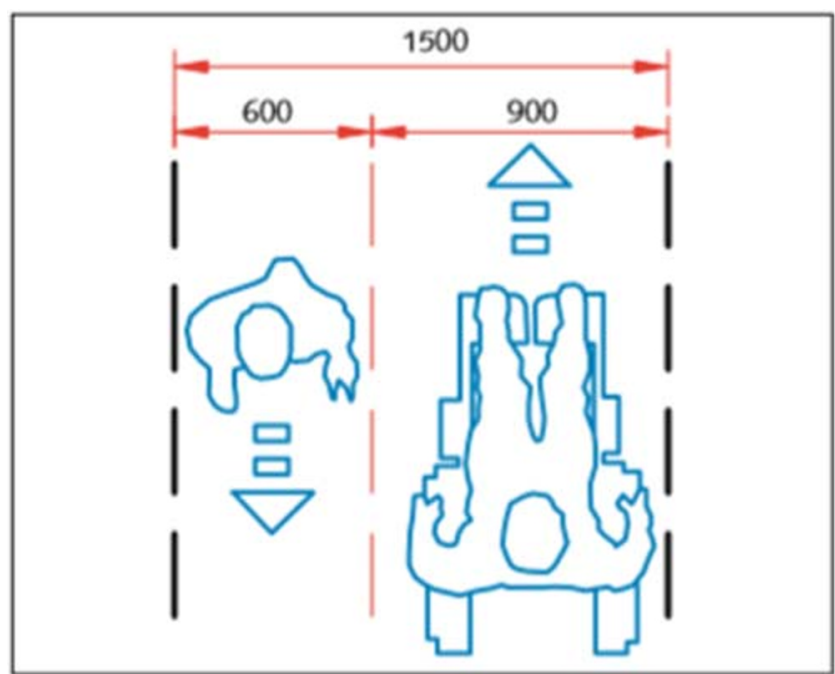

Fig. 4 Corridor width as recommended by UKDH [28]
However, there is no proof that mechanical ventilation has aided the spread of infection in houses even though a wide variety of micro-organism is said to have been found in vent outlet [33].

\section{Design to Enhance Daylight or Sunlight}

There is evidence that good fenestrations and daylight in structures can sway the spread of airborne pathogens. Evidently, before the advent of antibiotics, ventilation, and sunlight were thought to be a significant safety measures against infectious diseases [34]. Solly [35] added that direct sunlight through glass may well kill bacteria bacillus in a few minutes or hours subject to the thickness of the layer of bacteria exposed, moreover, diffuse sunlight found near windows in buildings may well kill bacteria in five to seven days. Advanced Studies indicated that sunlight can kill a variety of bacteria such as anthrax, tuberculosis, etc. [36]. A more recent study by Strong [37] posited that a diffused sunlight or daylight over two layers of glass from a north window was discovered to be very effective in killing hemolytic streptococci within thirteen days without antibiotics, with the similar strain surviving in the dark, at room temperature for one hundred and ninety-five (195) days. Daylighting is a good germicidal factor and can inhibit infection [5]. Lytle and Sagripanti [38] added that sunlight or, more specifically, solar radiation (UV) acts as the principal natural virucide in the environment. The standard for measuring daylight or sunlight is UV index and the germicidal effectiveness of UVC peaks at about 260$265 \mathrm{~nm}[39,40]$. It is important to note that the most effective and commonly used wavelength for ultraviolet germicidal irradiation (UVGI) is ultraviolet C [41]. Unfortunately, only a small percentage of it reaches the Earth's surface as most are absorbed by the ozone layer [42]. It simply follows that as part of infection prevention and control, there should be adequate openings that will allow daylight into hospital wards, rooms, offices corridors, and stairwell. Designing buildings with better exposure to sunlight and outdoor air may inhibit the 
Fig. 5 Suggested minimum Corridor width (Author)

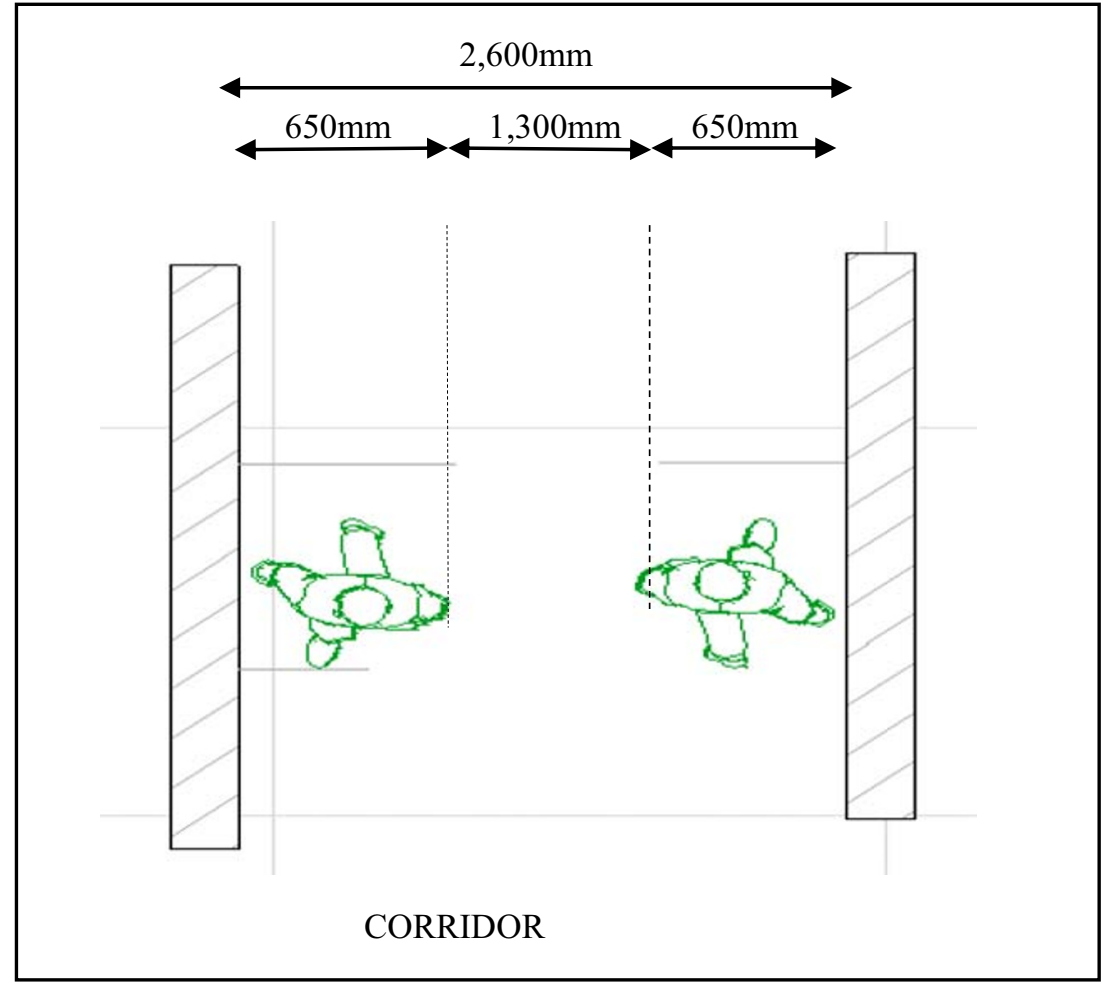

survival and transmission of infectious causes with resulting health benefits for dwellers.

\section{Design with adaptive finishing materials and construction methods}

Recent studies on coronavirus(covid-19) suggest that the virus behaves differently and possesses different life span with different material surfaces. A study by Doremalen et al. [23], shows that coronavirus is steadier on plastic

Table 1 The decay of droplet nuclei concentration for different ventilation rates and duration of time in a room. Hua et al. [30]

\begin{tabular}{lllll}
\hline \multirow{2}{*}{ Time (min) } & \multicolumn{4}{l}{ Ventilation rate (\%) } \\
\cline { 2 - 5 } & $6 \mathrm{ACH}$ & $12 \mathrm{ACH}$ & $18 \mathrm{ACH}$ & $24 \mathrm{ACH}$ \\
\hline 0 & 100 & 100 & 100 & 100 \\
5 & 60.7 & 36.8 & 22.37 & 13.5 \\
10 & 36.8 & 13.5 & 5.0 & $\mathbf{1 . 8}$ \\
15 & 22.3 & 5.00 & $\mathbf{1 . 1}$ & 0.3 \\
20 & 13.5 & $\mathbf{1 . 8}$ & 0.3 & 0.03 \\
25 & 8.2 & 0.7 & 0.06 & 0.00 \\
30 & 5.0 & 0.3 & 0.01 & 0 \\
40 & $\mathbf{1 . 8}$ & 0.03 & 0 & 0 \\
50 & 0.7 & 0 & 0 & 0 \\
60 & 0.3 & 0 & 0 & 0 \\
\hline
\end{tabular}

Source: Hua et al. [30] and steel (up to 3 days) than on spongy fabrics like cotton, leather, even cardboard $(<24 \mathrm{~h})$, while the same strain of the virus only survives for four (4) hours on copper surfaces. Thus, architects must rethink the material selection process, material specification writing and treatment of surfaces. An earlier study by Nightingale [34] revealed that the plaster used in construction, which has many tiny voids, was believed to be the breeding zone and spread of

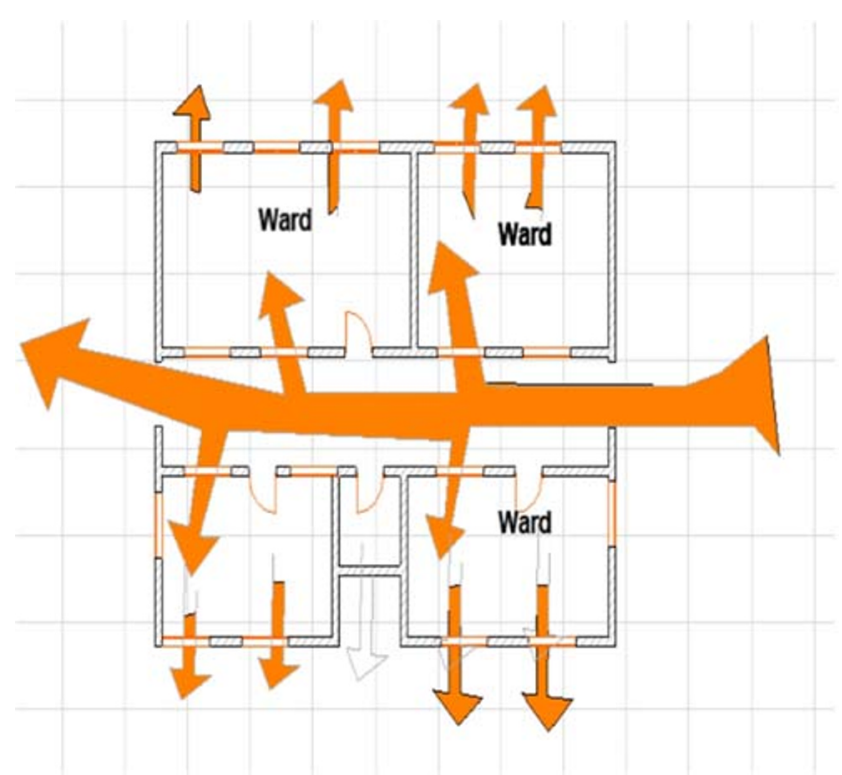

Fig. 6 Example of Open-end Corridor 
Fig. 7 Example of Court-Yard approach

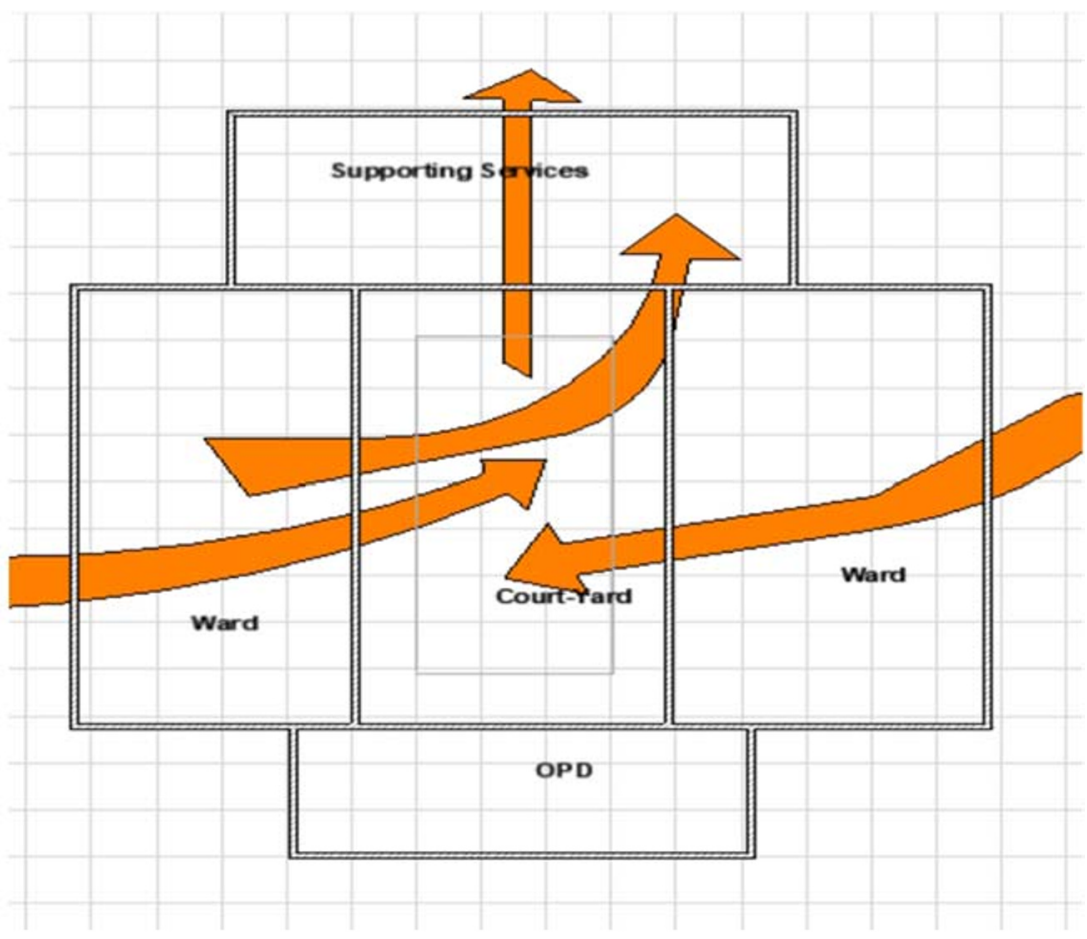

pathogenic elements. Based on the above findings, the study proposes the following;

- Specify Copper-infused or plated materials for frequently touched surfaces such as staircase handrails, balcony rails, bed rails.

- Design and situate sinks to enhance ease of cleaning and to prevent waste spilling to sensitive care areas.

- Plaster with a mixture of de-coagulant in cement screed or high solidity and smoothness. Apply POP screed after plastering with cement to enhance smoothness and eliminate tiny voids on the wall surface or use covering materials such as special paints, used of textured paints with fine sand should be discouraged.

- Entrance doors and curtains to hospitals and public spaces with high traffic should be designed with sensors to enhance automatic opening and closing. This will drastically reduce contact with the doorknob and hence prevent transmission.

- Multiple entrances into public spaces should be minimized, this is to enable effective monitoring of compliance to $\mathrm{CDC}$ rules.

- Sinks with motion sensors also to eliminate some possibilities of transmission. Controls and equipment should be specified with a smaller number of flat surfaces where particles can land as well as negligible crevices and crannies where debris can gather.

- Reducing the number of horizontal surfaces such as ledges can help reduce the spread of infection.

\section{Flexible design with sustainability features}

Provide well-organized and sufficient workspace to carry out a medication-related tasks. The design should not be rigid. But should be flexible enough to match with the changing health care demands and respond to up-to-date regulation from healthcare equipment manufacturers /providers and healthcare regulators. It is important to know that the ordinary existence of doors and windows is no assurance that they will be frequently used to enhance air movement as hospitals cannot automatically keep windows open during unfavorable climatic circumstances [43, 44]. Hence, a flexible design should be able to adapt to changes and accommodate new challenges such as the novel covid-19 pandemic.

The emergence of the novel coronavirus, increase in microbial resistance and lack of a vaccine for the present pandemic have made it imperative to appraise the preventive strategies employed during the pre-antibiotic period [45]. It is even more urgent as bioterrorism now poses an additional possible threat to public health indoors [46, 47]. Moreover, the modern architectural practice of designing healthcare buildings or hospitals for comfort and aesthetics favors pathogen persistence [40].

\section{Conclusion}

Thus, the paper surveys historical and contemporary proof supporting the influences of key design strategies -natural 
ventilation and daylight in decreasing the threat of infection in healthcare facilities. The study also examines the evolution of medical architecture, the connection between infectious diseases/architectural space, and suggested design approaches for infection prevention and control (IPC). The paper relied on an extensive review of existing literature in architecture, environmental science, and public health.

Design strategies can play a significant role in infection prevention and control (IPC). With the present effort to contend with the coronavirus (Covid-19) outbreak, it has become necessary that a multidisciplinary approach be adopted. It also proposes that architects and engineers directly involved in designing or constructing health-care facilities should be given a form of training in public health. This is because buildings designed with more or less daylight access could play a key role in influencing the microbial communities of indoor dust. Architects must rise to play their role in curbing the spread of coronavirus. This can be achieved at the early stage of design, specification writing, and construction. Daylight should be integrated into lighting design in hospital buildings, not only because it helps inhibit bacterial and virus infections but also because it will remove the need for artificial lighting, subsequently lead to energy conservation and contribute to environmental sustainability. Although UVC is the most effective wavelength for infection control only a small percentage reaches planet earth. The implication is that more daylight is needed in health-care facilities, schools, and indoors. The paper also suggests the use of special ultraviolet radiation systems (ultraviolet $\mathrm{C}$ lamps, chambers) especially in healthcare facilities where sunlight cannot be guaranteed.

\section{Compliance with ethical standards}

Conflict of interest The authors hereby declare that they have no conflict of interest.

And the authors have not received research grants from any company or agents.

Thanks.

Udomiaye Emmanuel.

\section{References}

1. Kim J. Sustainable architecture module: Introduction to sustainable design. NPPCHE. Ann Arbor, MI. 1998.

2. Van-Khai T. Adaptive Architecture and the Prevention of Infections in Hospitals. Civil Engineering Series. 2016;16(2): 2016-28.

3. WHO. Infection Prevention and Control. 2020. Retrieved from WHO: http://www.who.int. Accessed $23^{\text {rd }}$ May 2020.

4. Alcorn K. Tugela Ferry XDR-TB out Break Continues to Grow , but Treatment in KZN Provides Hope. 2007. Retrieved from namaidsmapp: https://www.aidsmap.com/news/nov-2007/tugela-ferryxdr-tb-outbreak.
5. Lateef F. Hospital Design for Infection Control. J Emerg ,Trauma Shock. 2009;2(3):175-9. https://doi.org/10.4103/0974-2700. 55329.

6. Wu X, Yongmei L, Zhou S, Chen L, Bing X. Impact of climate change on human infectious diseases: empirical evidence and human adaptation. Environ Int. 2016;86:14-23. https://doi.org/10. 1016/j.envint.2015.09.007.

7. Marlene C. Infectious Diseases Likes It Hot: How Climate Change Helps Cholera and Salmonella. 2015. Retrieved from ThinkProgress. https://archive.thinkprogress.org/infectiousdiseases. Accessed 17 May 2020.

8. CDCP (2019). Coronavirus Disease 2019. Retrieved from Center for Disease Control and Prevention: https://www.cdc.gov/ coronavirus/2019-ncov/preventgetting-sick/prevention.html. Accessed 17 May 2020.

9. Guenther R, Vittori G. Sustainable healthcare architecture. New Jersey: John Wiley and Sons; 2008.

10. Cameron L. International travels as medical research:architecture and the Mordern hospital. Health Hist. 2010;12(2):116-33. https://doi.org/10.5401/healthhist.12.2.0116.

11. Tesler N. Evolution of medical architecture. MATEC Web of Conferences 170, 03015. MATEC - EDP Sciences: Moscow; 2018. https://doi.org/10.1051/matecconf/201817003015.

12. Retief FP, Cilliers L. The Evolution of Hospital from the Renaissance 1. Acta theologica 2006;26(2). https://doi.org/10. 4314/actat.v26i2.52575.

13. Burpee H. History of Health Architecture. Integrated design Lab Puget. 2008. Retrieved from Mahlum: http://www.mahlum.com/ pdf/HistoryofHealthcareArchBurpee.pdf. Accessed 18 May 2020.

14. Costeira EMA. Healthcare Architecture: History, Evolution and New Visions. Sustinere. 2015. https://doi.org/10.13140/RG.2.1. 5103.6886.

15. Gormley T. History of Hospitals and Ward. Healthc Design. 2010;10(3):50-4.

16. Berche P. Louis Pasteur,From Crystals of Life to Vaccination. Clin Microbiol Infect. 2012;18(5):1-6. https://doi.org/10.1111/j.14690691.2012.03945.x.

17. Max EV. The modern Hospital in Historical Context. In: 31st annual international conference of the IEEE. Min. USA: EMBS; 2009.

18. Currie JM. The Fourth factor: A History Perspective on Architecture and Medicine. Washington, DC: AIA Press; 2007.

19. Young P, De Smith HV, Chambi M, Fin BC. Flourence Nightingale (1820-1910), 101 Years after her Death. Rev Med Chil. 2011;139(6):807-13.

20. Guiseppina LR, Marta F, Simonetta DL, Marcello, L, Michelo M. Viral Infections acquired Indoors through Airborne, Droplet or Contact Transmission. Annali dell'Istituto superiore di sanita 2013;49(2):124-32. https://doi.org/10.4415/ANN_13_02_03.

21. Verreault D, Moineau SD. Methods for Sampling of Airborne Viruses. Microbiol Mol Biol Rev. 2008;72(3):413-44. https://doi. org/10.1128/MMBR.00002-08.

22. Baker J, Stevens D, Bloomfield S. Spread and Prevention of Some Common Viral Infections in Community Facilities and Domestic. $J$ Appl Microbiol. 2001;91(1):7-21. https://doi.org/10.1046/j.23652672.2001.01364.x.

23. Doremalen NV, Trenton B, Dylan H, Myndi G, Amandine G, Brandi N, et al. Aerosol and Surface Stability of SARS-CoV-2 as Compared with SARS-CoV-1. New England J Med. 2020;382(16). https://doi.org/10.1056/NEJMc2004973.

24. Gleick P. Dirty water : Estimatined death from water related diseases 2000-2020. Environment and Security: Pacific Institute for Studies in Development; 2002.

25. Macy TI, Quick R. E. Transmission and Prevention of WaterRelated diseases. Uk: Eolss Pub.Ltd.; 2010. 
26. Christine LM. Waterborne Transmission of Infectious Agent. In: Crawford R, Garland J, Lipson D, Mills A, Stetzenbach L, editors. Manual of Environmental Microbology 3rd edition. Washington: ASM Press; 2007. p. 222-48. https://doi.org/10.1128/ 9781555815882.ch19.

27. Carthey J. Reinterpreting the Hospital Corridor - Waste Space or Essential multdisciplinary Clinical Care? Autumn 2008;2(1):1729. https://doi.org/10.1177/193758670800200103.

28. United Kingdom Department of Health (UKDH). Health Building Note 00-04-Circulation and Communication. London: UKDH. 2013

29. Zhao B, Jiang Y, Li X, Yang X, Zhang Y. Investigating a safe ventilation rate for the prevention of indoor SARS transmission :an Attemp based on simulation approach. Build Simul. 2009;2: 281-9.

30. Hua Q, Yuguo L, Seto W, Patricia C, Ching W, Sun H. Natural Ventilation for reducing Airborne Infection in Hospital. Build Environ. 2010;45(3):1651-8.

31. Wang J, Huang L, Jiang S, Chen X, Wu W, Yin S, et al. Ventilation of wards and Noscomial outbreak of severe acute respiratory Sydrome among health workers. Chin Med Journal. 2003;116(9): 1293-7.

32. Ninomura P, Bartley J. New Ventilation Guidelines for Health-Care Facilities. ASHRAE Journal. 2001;43(6):29-33.

33. Escombe A, Eduardo T, Victor C-P, Manuel E, David, A.. Improving Natural Ventilation in Hospitals Waiting and Consulting Rooms to Reduce Nosocomial Tuberculosis Risk in a Low Resources Setting. BMC Infectious Diseases 2019;19(1). https://doi.org/10.1186/s12879-019-3717-9.

34. Nightingale F. Notes on hospitals 3rd ed. London: Longman, Robert \& Green; 1868.

35. Solly SE. A hand book on medical climatology. Lea Brothers \& Co: Philadelphia anf New York; 1897.

36. Hockberger P. The damaging effects of sunlight on bacteria. J Photochem Photobiol. 2000;58:155-91.

37. Strong P. Daylight Benefit in Healthcare Buildings. Designing Buildings-BR group. 2020.https://www.designingbuildings.co.uk/
w/images/2/22/David_Strong_(2of2)Daylight_Benefits_in Healthcare_buildgs-BRGroup. Accessed 23 May 2020.

38. Lytle D, Sagripanti J-L. Predicted Inactivation of Viruses of Relevance of Biodefence by Solar Radiation. J Virol. 2005;79(22):14244-142252. https://doi.org/10.1128/JVI.79.22. 14252.

39. Rauth AM. The physical state of viral nucleic acid and the sensitivity of viruses to ultraviolet light. Biophys J. 1965;5(3):257-73. https://doi.org/10.1016/s0006-3495(65)86715-7.

40. Seyer A, Sanlidag T. Solar ultraviolet radiation sensitivity of SARS-CoV-2. Lancet Microbe. 2020;1(1):e8-9. https://doi.org/ 10.1016/S2666-5247(20)30013-6.

41. Kowalski WJ. Ultraviolet germicidal irradiation handbook. Springer; Berlin: 2009. https://doi.org/10.1007/978-3-642-019999_2.

42. Pozo-Antonio JS, Sanmartín P. Exposure to artificial daylight or UV irradiation ( $\mathrm{a}, \mathrm{B}$ or $\mathrm{C}$ ) prior to chemical cleaning: an effective combination for removing phototrophs from granite. Biofouling. 2018;34:851-69.

43. Aikinson, J., Chartler, Y., \& Pessoa, S. P. Natural ventilation for infection control in health-care setting. World Health Organisation.Geneva. 2009.

44. Hobday R, Dancer S. Role of sunlight and natural ventilation for controlling infection: historical and current perspective. J Hospital Infect. 2013;84(4). https://doi.org/10.1016/J.Jhin.2013.04.011.

45. Gould I. Antibiotic Resistance:The Perfect Storm. Int. J AntiMicrob Agent. 2009;34:52-5.

46. Wallin A, Lukslene Z, Zagminas K, Surklene G. Public Health and Bioterroism:Renewed Threat of Anthrax and Smallpox. Medicina(Kaunas). 2007;43:278-84.

47. Fleck F. Conference Warns of Danger of Re-emergence of Smallpox as Weapon of Bioterror. Bull WHO. 2003;81:917-8.

Publisher's note Springer Nature remains neutral with regard to jurisdictional claims in published maps and institutional affiliations. 